\title{
Extracorporeal cardiopulmonary resuscitation
}

\author{
Nicholson Yam, David Michael McMullan \\ Division of Cardiac Surgery, Seattle Children's Hospital, Seattle, WA, USA \\ Contributions: (I) Conception and design: DM McMullan; (II) Administrative support: DM McMullan; (III) Provision of study materials or patients: \\ All authors; (IV) Collection and assembly of data: All authors; (V) Data analysis and interpretation: All authors; (VI) Manuscript writing: All authors; \\ (VII) Final approval of manuscript: All authors. \\ Correspondence to: David Michael McMullan. Division of Cardiac Surgery, Seattle Children's Hospital, 4800 Sand Point Way NE, Seattle, Washington \\ 98105, USA. Email: david.mcmullan@seattlechildrens.org.
}

\begin{abstract}
Extracorporeal life support (ECLS) is used for patients in isolated or combined cardiopulmonary failures. The use of ECLS to rescue patients with cardiac arrest that is refractory to conventional cardiopulmonary resuscitation has been shown to improve survival in many patient populations. Increasing recognition of the survival benefit associated with extracorporeal cardiopulmonary resuscitation (ECPR) has led to increased use of ECPR during the past decade. This review provides an overview of ECPR utilization; population-based clinical outcomes, resource utilization and costs associated this advanced form of life support therapy.
\end{abstract}

Keywords: Cardiac arrest; extracorporeal life support (ECLS); extracorporeal membrane oxygenation; cardiopulmonary resuscitation $(\mathrm{CPR})$

Submitted Oct 26, 2016. Accepted for publication Nov 08, 2016.

doi: 10.21037/atm.2017.01.11

View this article at: http://dx.doi.org/10.21037/atm.2017.01.11

Each year approximately 350,000 people experience cardiac arrest in the United States (1). Even though cardiac arrest occurs less frequently in children than adults, approximately 16,000 American children experience out-of-hospital cardiac arrest annually (2) and $1-2 \%$ of pediatric hospital admissions result in cardiopulmonary resuscitation (CPR) $(3,4)$. Overall survival for children who experience out-ofhospital cardiac arrest is less than $10 \%$, whereas in-hospital cardiac arrest survival is $>40 \%$ in this population (5). In comparison, the survival rate for adults who experience inhospital cardiac arrest remains only $22 \%$ despite modest improvement during the past two decades $(6,7)$. American Heart Association guidelines recommend prompt initiation of conventional CPR to provide effective end-organ oxygen delivery, especially the heart and brain $(5,8)$.

Extracorporeal life support (ECLS) is a now widely available form of advanced mechanical therapy that provides cardiovascular support for patients with refractory, lifethreatening cardiopulmonary failure. The Extracorporeal Life Support Organization (ELSO) international registry contains clinical data from over 82,000 patients who have received ECLS during the past three decades (9).
Overall ECLS survival has remained relatively stable at approximately $60 \%$ but is much higher in unique patient populations such as neonates (74\% survival). Survival in patients who receive ECLS for cardiac arrest that is refractory to conventional CPR [extracorporeal cardiopulmonary resuscitation (ECPR)] is lower than overall ECLS survival, with only $29 \%$ of adults and $41 \%$ of neonates and children surviving ECPR (9). Overall survival for neonates receiving ECPR is similar to older pediatric patients but decreases with lower gestational age and weight. Despite this, many low-birth weight neonates survive to hospital discharge (10).

Since initial reports in the 1990's describing of the successful application of ECLS to provide life-saving circulatory support for patients in refractory cardiac arrest (11-13), many centers have adopted ECPR as a clinically accepted approach to supporting patients with refractory cardiac arrest. The number of ECPR patients increased by greater than ten-fold since 2004 (565 patients) and there are now more than 7,000 ECPR patients in the ELSO registry $(9,14)$. Moreover, the proportion patients who received ECLS for cardiac arrest has increased slightly during the 
past decade, with ECPR patients now represent nearly $9 \%$ of ELSO registry data $(15,16)$. Although a prospective randomize study has not been performed to evaluate the true clinical impact of ECPR on patient survival, propensity-score based analyses and multiple center-based reports suggest that incorporation of ECLS into standard resuscitation protocols has likely saved the life of thousands of patients who have experienced life-threatening refractory cardiac arrest (9). The beneficial impact of ECPR on survival was highlighted in two recent meta-analyses of studies that compared ECPR to conventional CPR in adults $(17,18)$. Although little difference in out-of-hospital cardiac arrest survival was observed, improved overall survival and neurologic outcome at 3-6 months in patients who received ECPR for in-hospital cardiac arrest. Broad evidence for improved survival following ECPR led to the American Heart Association's recommended in 2015 that consideration be given for ECPR in potentially reversible cardiac arrest in adults if extracorporeal support can be rapidly implemented (5). Furthermore, consideration should be given to ECPR for pediatric patients with an underlying cardiac diagnosis who experience in-hospital cardiac arrest when ECLS expertise is available $(5,8)$. Data from the ELSO registry indicates that $41 \%$ overall ECPR survival in neonates and children and 30\% overall ECPR in adult patients $(15,16)$. While it is increasingly clear that ECPR is associated with improved survival following refractory cardiac arrest, adequate pre-ECPR resuscitation, efficient implementation of extracorporeal support, and appropriate patient selection are undoubtedly the most important determinants of survival. Several modifiable and nonmodifiable factors are believed to impact ECPR outcomes.

\section{Location}

However, studies comparing outcomes in out-of-hospital $v s$. in-hospital cardiac arrest suggest that survival is better in patients who experience in-hospital cardiac arrest (19). The previously discussed meta-analysis failed to identify a clear survival benefit in patents who experienced outof-hospital cardiac arrest, whereas a survival benefit was observed in hospitalized patients who experienced cardiac arrest (18). A detailed analysis by Jaski et al. showed that ECPR performed in the catheterization laboratory was associated with significantly better survival than in other hospital locations $(50 \%$ vs. $15 \%$ long-term survival, $\mathrm{P} \leq 0.001)(20)$. Immediate availability of ECLS equipment and skilled personnel in the catheterization laboratory may play a role in the improved survival rate observed in these patients. Survival has been reported to decrease by $5 \%$ with each elapsed minute of CPR (3). Clinical reports of ECPR for out-of-hospital cardiac arrest typically describe longer ECLS initiation time and extended periods of inadequate cerebral and myocardial oxygen delivery (21).

\section{Duration of pre-ECPR resuscitation}

Early implementation of appropriately performed CPR is associated with improved survival (22). There is currently no consensus regarding the impact of CPR duration on ECPR survival. Duration of CPR was not identified as an independent risk factor for mortality in retrospective review of the American Heart Association National Registry of CPR (23). However, duration of CPR was identified as is a strong predictor of survival in a recent large, singlecenter study ( 15 min survivors vs. $40 \mathrm{~min}$ non-survivors, $\mathrm{P}=0.009$ ), in which children who required $\geq 30 \mathrm{~min}$ of $\mathrm{CPR}$ had $79 \%$ reduced odds of hospital survival (24). Several single-center published reports do not identify duration of CPR as a predictor of ECPR survival but the difference in median duration of CPR between survivors and nonsurvivors was generally small $(<5 \mathrm{~min})(25-27)$. In contrast, pre-ECLS resuscitation $>30$ minutes has been identified as a significant independent risk factor of mortality in adults who experience out-of-hospital cardiac arrest (28). Results of a large observational-based propensity analysis indicate that ECPR survival declines with increased duration of preECPR resuscitation (29). Despite this finding, a survival benefit of ECPR was observed even after prolonged $(>60$ min) CPR, with $18 \%$ ECPR vs. $0 \%$ conventional CPR patients in this category surviving to hospital discharge. Currently available data do not support the use of duration of pre-ECLS resuscitation as a contraindication to ECPR but suggest that the shorter duration $(\leq 30 \mathrm{~min})$ of ECLS resuscitation is associated with better survival $(24,30)$.

In programs that provide ECPR, quality improvement programs should focus on adequacy of conventional preECLS resuscitation and hospital resources should be allocated in ways that reduce unnecessary delays in initiation of ECLS.

\section{Etiology of cardiac arrest}

Several studies have examined the impact of underlying cause of cardiac arrest on ECPR survival. Some centers have reported approximately four-fold better survival in 
patients who experience cardiac arrest due to primarily cardiac failure than those with an underlying non-cardiac abnormality $(31,32)$. Although these studies were not designed to identify reasons for etiology-based differences in ECPR outcomes, one might speculate that patients with a primarily cardiac cause of failure are more likely to have single (cardiovascular) system pathology that may exhibit recovery or is amenable to corrective intervention, whereas patients with non-cardiac causes of cardiac arrest are at greater risk of having or developing multi-organ pathology that is less amenable to recovery during ECLS. An analysis of 682 pediatric ECPR patients in the ELSO registry found that underlying cardiac diagnosis is an independent predictor of improved survival (15). Similarly, a study of 295 adult ECPR patients in the ELSO registry demonstrated superior survival among patients with underlying cardiac pathology vs. a non-cardiac reason for cardiac arrest (16). An underlying diagnosis of acute myocarditis was associated with greatest survival in the logistic regression analysis. Overall survival was $27 \%$, with brain death occurring in $28 \%$ of non-survivors.

Life-threatening septicemia, once considered a contraindication to ECLS, is now increasingly being managed with ECLS, with neonatal sepsis ECLS survival as high as $72 \%$ (9). The American College of Critical Care Medicine guidelines now included ECLS in the treatment algorithm for refractory shock in neonatal and pediatric sepsis (33). In a review of children managed with ECLS for refractory septic shock with multi-organ failure, $40 \%$ of patients progressed to cardiac arrest and required CPR before ECLS (34). Overall survival in this series was $47 \%$, highlighting the potential benefit of ECPR in patients who experience hemodynamic instability and cardiac arrest due to overwhelming sepsis.

ECLS has been used in the management of victims of accidental severe hypothermia and drowning, which may lead to life-threatening dysrhythmia and cardiac arrests. In a study from Denmark, ECLS was used to successfully rescued all members of a group of cold water drowning accident victims who experienced deep hypothermic cardiac arrest (35). An analysis of 12 pediatric victims of accidental hypothermia and cardiac arrests also reports long-term survivors, albeit with a number of survivors experiencing long-term neurological sequelae from hypoxic brain injury (36). Another report describes $33 \%$ survival in a group of 15 adult victims of hypothermia-induced cardiac arrest (37). Despite prolonged cardiac arrest and ECPR, all but one of the seven survivors was neurologically intact at longterm follow-up. Data from the ELSO registry indicates that survival in patients who undergo ECPR for drowningrelated cardiac arrest is $23.4 \%$, which is lower than the survival rate observed in patients who experienced cardiac arrest but achieved return of spontaneous circulation prior to ECLS (57\%) (38).

Mechanical cardiopulmonary support may also be used in patients who experience cardiopulmonary failure due to ingestion of cardiotoxic chemicals or pharmaceutical agents. Commonly ingested and agents included beta-blockers, calcium-channel blockers, tricyclic antidepressants (39). ECLS may be used to provide cardiopulmonary support until the clinical effects of the intoxicating agent have resolved or until effective pharmacologic treatment. In a report of ten patients with refractory and prolonged druginduced cardiac arrest, $86 \%$ of patients who received ECPR survived, compared to $48 \%$ survival in the conventionallymanaged group (40).

\section{Therapeutic hypothermia during ECPR}

Patients who require ECPR are at risk for brain injury. Preliminary reports from clinical trials published in 2002 suggested that moderate therapeutic hypothermia may provide some neurologic protection for comatose adults following out-of-hospital cardiac arrest $(41,42)$. Therapeutic hypothermia has also been shown to improve neonatal hypoxic ischemic encephalopathy in several clinical reports (43). However, results from a recently published prospective clinical trial of therapeutic hypothermia after out-of-hospital cardiac arrest in children found that therapeutic hypothermia did not confer a significant benefit in survival with a good functional outcome at 1 year (44). Although there is currently no strong evidence for or consensus related to the use of therapeutic hypothermia during ECPR, current guidelines from ELSO emphasize the importance of central nervous system protection in ECPR patients based on expert opinion (45). Recommendations include topic cerebral cooling with ice during CPR and for 48-72 hours after initiation of ECLS cannulation. Fever has been identified as an important risk factor for poor neurological recovery in children who experience cardiac arrest (46). Integrated heat exchangers enable targeted and accurate systemic temperature control during ECLS. Targeted temperature regulation to avoid hyperthermia following cardiac arrest should be considered in ECPR patients. 


\section{ECPR program organization}

Urgent initiation of ECLS for cardiac arrest that is refractory to conventional CPR has been successfully performed in centers with little ECLS experience and in remote locations (47). An increasing number of hospital systems are allocating resources to incorporate ECPR into existing resuscitation programs. Ultimately, the goal of these programs is to reduce barriers to appropriate and expedient initiation of mechanical cardiopulmonary support. The organizational structure of a hospital-based ECPR program must be based on available assets, personnel, and ECLS experience. Although ECPR programs must ultimately be designed to complement a hospital's unique clinical environment, a number of programmatic factors are common to most highly functioning ECPR programs. In general, decision-making related to utilization of ECLS should be anticipatory, with a pre-designated individual (e.g., CPR Code Team Leader) who is authorized to request ECPR. Universal ECPR inclusion and exclusion criteria do not exist but there is general agreement that patients with certain clinical conditions, such as uncontrolled hemorrhage, recent cerebral hemorrhage, and end-stage terminal illness, are poor candidates for ECPR. The availability of rapidly deployable ECLS equipment and personnel is essential to prevent unnecessary delays in establishing extracorporeal support. ECPR equipment is not standardized and varies according to hospital environment (48). Many hospitals maintain much of the necessary ECPR circuitry and components as part of a cardiac surgery program, whereas ECLS equipment may need to be purchased in facilities that do not perform cardiac surgery. Portable vascular ultrasound is an invaluable aid during vascular cannulation for ECPR (49). In-house ECPR teams are commonly utilized but not always necessary. Centers have reported successful ECPR programs that utilize offsite personnel (50). The ECPR team typically includes surgeon, perfusionists or ECLS specialist technicians, intensive care specialists, and specialized nurses. Intensive care specialists experienced with ECLS cannulation perform percutaneous ECPR cannulation in some centres. A recent survey of US centers that perform emergency room ECLS suggested that $15 \%$ of emergency department-based ECLS programs do not utilize cardiothoracic surgeons (51).

\section{Cost}

The cost for salvage ECLS in pediatric heart disease has been estimated at USD $\$ 24,386$ per quality-adjusted life years, with a median post-arrest hospitalization cost of USD \$156,324 per patient (52). By comparison, the cost of maintenance renal dialysis is USD $\$ 50,000$ per qualityadjusted life year and the cost of heart transplantation is estimated to be USD $\$ 49,697$ per quality-adjusted life year (53). The cost of providing ECLS care is highly variable (54) and directly related to many factors, including advanced ECLS equipment, broad multi-disciplinary team involvement, and increased acuity and length of care. Decision making related to developing or maintaining an ECPR program must weigh hospital economics, societal and cultural beliefs, and local sociopolitical factors. In some cases, prolonged ECLS following cardiac arrest may be determined to be futile, which may raise ethical issues among care providers and patient family members. It is important to regularly review therapeutic goals and clinical progress and to maintain open between the care team and the patient/family to facilitate well-informed medical decisions (55).

Greater appreciation of the survival benefit of ECPR for refractory cardiac arrest is encouraging more centers to develop and maintain an ECPR program. Clinical experience and large registry data support the use of ECPR in many patient populations and age groups. The observed survival benefit is compelling enough that a randomized, prospective study comparing ECPR vs. conventional CPR is not likely to be performed. Clinical data from ECPR patients should reported to the ELSO registry to facilitate future studies designed to improve patient selection and identify potentially modifiable risk factors poor ECPR outcome.

\section{Acknowledgements}

None.

\section{Footnote}

Conflicts of Interest: The authors have no conflicts of interest to declare.

\section{References}

1. Cooper JA, Cooper JD, Cooper JM. Cardiopulmonary resuscitation: history, current practice, and future direction. Circulation 2006;114:2839-49.

2. Atkins DL, Everson-Stewart S, Sears GK, et al. 
Epidemiology and outcomes from out-of-hospital cardiac arrest in children: the Resuscitation Outcomes Consortium Epistry-Cardiac Arrest. Circulation 2009;119:1484-91.

3. Reis AG, Nadkarni V, Perondi MB, et al. A prospective investigation into the epidemiology of in-hospital pediatric cardiopulmonary resuscitation using the international Utstein reporting style. Pediatrics 2002;109:200-9.

4. Suominen P, Olkkola KT, Voipio V, et al. Utstein style reporting of in-hospital paediatric cardiopulmonary resuscitation. Resuscitation 2000;45:17-25.

5. de Caen AR, Berg MD, Chameides L, et al. Part 12: Pediatric Advanced Life Support: 2015 American Heart Association Guidelines Update for Cardiopulmonary Resuscitation and Emergency Cardiovascular Care. Circulation 2015;132:S526-42.

6. Goldberger ZD, Chan PS, Berg RA, et al. Duration of resuscitation efforts and survival after in-hospital cardiac arrest: an observational study. Lancet 2012;380:1473-81.

7. Meaney PA, Nadkarni VM, Kern KB, et al. Rhythms and outcomes of adult in-hospital cardiac arrest. Crit Care Med 2010;38:101-8.

8. Link MS, Berkow LC, Kudenchuk PJ, et al. Part 7: Adult Advanced Cardiovascular Life Support: 2015 American Heart Association Guidelines Update for Cardiopulmonary Resuscitation and Emergency Cardiovascular Care. Circulation 2015;132:S444-64.

9. Extracorporeal Life Support Organization Registry Report: International Summary. Extracorporeal Life Support Organization (ELSO), 2016. Available online: https://www.elso.org/Registry/Statistics/Reports.aspx

10. McMullan DM, Thiagarajan RR, Smith KM, et al. Extracorporeal cardiopulmonary resuscitation outcomes in term and premature neonates*. Pediatr Crit Care Med 2014;15:e9-e16.

11. Hill JG, Bruhn PS, Cohen SE, et al. Emergent applications of cardiopulmonary support: a multiinstitutional experience. Ann Thorac Surg 1992;54:699-704.

12. Mooney MR, Arom KV, Joyce LD, et al. Emergency cardiopulmonary bypass support in patients with cardiac arrest. J Thorac Cardiovasc Surg 1991;101:450-4.

13. del Nido PJ, Dalton HJ, Thompson AE, et al. Extracorporeal membrane oxygenator rescue in children during cardiac arrest after cardiac surgery. Circulation 1992;86:II300-4.

14. Conrad SA, Rycus PT, Dalton H. Extracorporeal Life Support Registry Report 2004. ASAIO J 2005;51:4-10.

15. Thiagarajan RR, Laussen PC, Rycus PT, et al. Extracorporeal membrane oxygenation to aid cardiopulmonary resuscitation in infants and children. Circulation 2007;116:1693-700.

16. Thiagarajan RR, Brogan TV, Scheurer MA, et al. Extracorporeal membrane oxygenation to support cardiopulmonary resuscitation in adults. Ann Thorac Surg 2009;87:778-85.

17. Ahn C, Kim W, Cho Y, et al. Efficacy of extracorporeal cardiopulmonary resuscitation compared to conventional cardiopulmonary resuscitation for adult cardiac arrest patients: a systematic review and meta-analysis. Sci Rep 2016;6:34208.

18. Kim SJ, Kim HJ, Lee HY, et al. Comparing extracorporeal cardiopulmonary resuscitation with conventional cardiopulmonary resuscitation: A meta-analysis. Resuscitation 2016;103:106-16.

19. Kagawa E, Inoue I, Kawagoe T, et al. Assessment of outcomes and differences between in- and out-of-hospital cardiac arrest patients treated with cardiopulmonary resuscitation using extracorporeal life support. Resuscitation 2010;81:968-73.

20. Jaski BE, Ortiz B, Alla KR, et al. A 20-year experience with urgent percutaneous cardiopulmonary bypass for salvage of potential survivors of refractory cardiovascular collapse. J Thorac Cardiovasc Surg 2010;139:753-7.e1-2.

21. Fagnoul D, Combes A, De Backer D. Extracorporeal cardiopulmonary resuscitation. Curr Opin Crit Care 2014;20:259-65.

22. Ritter G, Wolfe RA, Goldstein S, et al. The effect of bystander CPR on survival of out-of-hospital cardiac arrest victims. Am Heart J 1985;110:932-7.

23. Raymond TT, Cunnyngham CB, Thompson MT, et al. Outcomes among neonates, infants, and children after extracorporeal cardiopulmonary resuscitation for refractory inhospital pediatric cardiac arrest: a report from the National Registry of Cardiopulmonary Resuscitation. Pediatr Crit Care Med 2010;11:362-71.

24. Sivarajan VB, Best D, Brizard CP, et al. Duration of resuscitation prior to rescue extracorporeal membrane oxygenation impacts outcome in children with heart disease. Intensive Care Med 2011;37:853-60.

25. Wolf MJ, Kanter KR, Kirshbom PM, et al. Extracorporeal cardiopulmonary resuscitation for pediatric cardiac patients. Ann Thorac Surg 2012;94:8749; discussion 879-80.

26. Kane DA, Thiagarajan RR, Wypij D, et al. Rapidresponse extracorporeal membrane oxygenation to support cardiopulmonary resuscitation in children with cardiac disease. Circulation 2010;122:S241-8. 
27. Polimenakos AC, Wojtyla P, Smith PJ, et al. Postcardiotomy extracorporeal cardiopulmonary resuscitation in neonates with complex single ventricle: analysis of outcomes. Eur J Cardiothorac Surg 2011;40:1396-405; discussion 1405.

28. Leick J, Liebetrau C, Szardien S, et al. Door-toimplantation time of extracorporeal life support systems predicts mortality in patients with out-of-hospital cardiac arrest. Clin Res Cardiol 2013;102:661-9.

29. Chen YS, Lin JW, Yu HY, et al. Cardiopulmonary resuscitation with assisted extracorporeal life-support versus conventional cardiopulmonary resuscitation in adults with in-hospital cardiac arrest: an observational study and propensity analysis. Lancet 2008;372:554-61.

30. Alsoufi B, Awan A, Manlhiot C, et al. Does single ventricle physiology affect survival of children requiring extracorporeal membrane oxygenation support following cardiac surgery? World J Pediatr Congenit Heart Surg 2014;5:7-15.

31. Alsoufi B, Al-Radi OO, Nazer RI, et al. Survival outcomes after rescue extracorporeal cardiopulmonary resuscitation in pediatric patients with refractory cardiac arrest. J Thorac Cardiovasc Surg 2007;134:952-959.e2.

32. Morris MC, Wernovsky G, Nadkarni VM. Survival outcomes after extracorporeal cardiopulmonary resuscitation instituted during active chest compressions following refractory in-hospital pediatric cardiac arrest. Pediatr Crit Care Med 2004;5:440-6.

33. Brierley J, Carcillo JA, Choong K, et al. Clinical practice parameters for hemodynamic support of pediatric and neonatal septic shock: 2007 update from the American College of Critical Care Medicine. Crit Care Med 2009;37:666-88.

34. Maclaren G, Butt W, Best D, et al. Extracorporeal membrane oxygenation for refractory septic shock in children: one institution's experience. Pediatr Crit Care Med 2007;8:447-51.

35. Wanscher M, Agersnap L, Ravn J, et al. Outcome of accidental hypothermia with or without circulatory arrest: experience from the Danish Præstø Fjord boating accident. Resuscitation 2012;83:1078-84.

36. Wollenek G, Honarwar N, Golej J, et al. Cold water submersion and cardiac arrest in treatment of severe hypothermia with cardiopulmonary bypass. Resuscitation 2002;52:255-63.

37. Walpoth BH, Walpoth-Aslan BN, Mattle HP, et al. Outcome of survivors of accidental deep hypothermia and circulatory arrest treated with extracorporeal blood warming. N Engl J Med 1997;337:1500-5.

38. Burke CR, Chan T, Brogan TV, et al. Extracorporeal life support for victims of drowning. Resuscitation 2016;104:19-23.

39. de Lange DW, Sikma MA, Meulenbelt J. Extracorporeal membrane oxygenation in the treatment of poisoned patients. Clin Toxicol (Phila) 2013;51:385-93.

40. Masson R, Colas V, Parienti JJ, et al. A comparison of survival with and without extracorporeal life support treatment for severe poisoning due to drug intoxication. Resuscitation 2012;83:1413-7.

41. Bernard SA, Gray TW, Buist MD, et al. Treatment of comatose survivors of out-of-hospital cardiac arrest with induced hypothermia. N Engl J Med 2002;346:557-63.

42. Group HaCAS. Mild therapeutic hypothermia to improve the neurologic outcome after cardiac arrest. N Engl J Med 2002;346:549-56.

43. Tagin MA, Woolcott CG, Vincer MJ, et al. Hypothermia for neonatal hypoxic ischemic encephalopathy: an updated systematic review and meta-analysis. Arch Pediatr Adolesc Med 2012;166:558-66.

44. Moler FW, Silverstein FS, Holubkov R, et al. Therapeutic hypothermia after out-of-hospital cardiac arrest in children. N Engl J Med 2015;372:1898-908.

45. Guidelines for ECPR Cases Version 1.3. Extracorporeal Life Support Organization (ELSO), 2013. Available online: https://www.elso.org/Registry/Statistics/Reports.aspx

46. Bembea MM, Nadkarni VM, Diener-West M, et al. Temperature patterns in the early postresuscitation period after pediatric inhospital cardiac arrest. Pediatr Crit Care Med 2010;11:723-30.

47. McMullan DM. Expanding the availability of extracorporeal cardiopulmonary resuscitation. Pediatrics 2013;131:e934-8.

48. Swol J, Belohlávek J, Haft JW, et al. Conditions and procedures for in-hospital extracorporeal life support (ECLS) in cardiopulmonary resuscitation (CPR) of adult patients. Perfusion 2016;31:182-8.

49. Hilty WM, Hudson PA, Levitt MA, et al. Real-time ultrasound-guided femoral vein catheterization during cardiopulmonary resuscitation. Ann Emerg Med 1997;29:331-6; discussion 337.

50. Ghez O, Fouilloux V, Charpentier A, et al. Absence of rapid deployment extracorporeal membrane oxygenation (ECMO) team does not preclude resuscitation ecmo in pediatric cardiac patients with good results. ASAIO J 2007;53:692-5.

51. Tonna JE, Johnson NJ, Greenwood J, et al. Practice 
characteristics of Emergency Department extracorporeal cardiopulmonary resuscitation (eCPR) programs in the United States: The current state of the art of Emergency Department extracorporeal membrane oxygenation (ED ECMO). Resuscitation 2016;107:38-46.

52. Mahle WT, Forbess JM, Kirshbom PM, et al. Costutility analysis of salvage cardiac extracorporeal membrane oxygenation in children. J Thorac Cardiovasc Surg 2005;129:1084-90.

53. Dayton JD, Kanter KR, Vincent RN, et al. Cost-

Cite this article as: Yam N, McMullan DM. Extracorporeal cardiopulmonary resuscitation. Ann Transl Med 2017;5(4):72. doi: 10.21037/atm.2017.01.11 effectiveness of pediatric heart transplantation. J Heart Lung Transplant 2006;25:409-15.

54. Harvey MJ, Gaies MG, Prosser LA. U.S. and International In-Hospital Costs of Extracorporeal Membrane Oxygenation: a Systematic Review. Appl Health Econ Health Policy 2015;13:341-57.

55. Meltzer EC, Ivascu NS, Acres CA, et al. Extracorporeal membrane oxygenation in adults: a brief review and ethical considerations for nonspecialist health providers and hospitalists. J Hosp Med 2014;9:808-13. 